\title{
Sensitive Artemisinin Electrochemical Sensor Based on Polymerized Molecularly Imprinted Membranes
}

\author{
Ji Zhou, Xinyu Sun and Kai Wang ${ }^{*}$ \\ Hubei Novel Reactor \& Green Chemical Technology Key Laboratory, Key Laboratory for Green \\ Chemical Process of Ministry of Education, Wuhan Institute of Technology, Wuhan 430073, P. R. \\ China \\ *E-mail: kaiwang_wit@yahoo.com
}

doi: $10.20964 / 110403114$

Received: 24 January 2016 / Accepted: 22 February 2016 / Published: 1 March 2016

\begin{abstract}
An electrochemical molecular imprinted sensor was successfully developed for ultra-sensitive detection of artemisinin (AN). The electrochemical sensor was fabricated on a poly(diallyldimethylammonium) chloride-reduced graphene oxide (PDDA-RGO) functionalized glassy carbon electrode (GCE) using acrylamide (AM) and ethylene glycol dimethacrylate (EGD) as monomer and cross-linking agent, respectively. The fabricated AN sensor was characterized by different techniques. After optimization of experimental parameters, the proposed AN sensor showed a wide detection linear range, low detection limit, excellent sensitivity and selectivity. The practical performance of the AN sensor showed an accurate determination of AN in Artemisia annua L extract.
\end{abstract}

Keywords: Molecularly imprint; Artemisinin; Graphene; Acrylamide; Electrochemical sensor

\section{$\underline{\text { FULL TEXT }}$}

(C) 2016 The Authors. Published by ESG (www.electrochemsci.org). This article is an open access article distributed under the terms and conditions of the Creative Commons Attribution license (http://creativecommons.org/licenses/by/4.0/). 